\title{
THIOSULPHATE CLEARANCE IN PREGNANCY
}

\author{
By CLAUDINE LAMBIOTTE, ${ }^{1}$ JOSEPH BLANCHARD, ANd SAMUEL GRAFF \\ WITH THE TECHNICAL ASSISTANCE OF ADA GRAFF
}

\begin{abstract}
(From the Clinique de Gynécologie et Obstétrique du Professeur J. Snoeck, Hôpital St. Pierre, Universite Libre de Bruxelles, and the Department of Gynecology and Obstetrics, College of Physicians and Surgeons, Columbia University and the Sloane Hospital for Women, New York City)
\end{abstract}

(Submitted for publication February 13, 1950; accepted, June 12, 1950)

In 1946, Gilman, Philips, and Koelle (1) reported observations on the renal clearance of thiosulphate in dogs. In 13 experiments, comprising 46 clearance periods, they found that the creatinine/thiosulphate clearance ratio fell within the range of 0.9 to 1.1 . They concluded that thiosulphate is unique among inorganic ions in that it is neither reabsorbed nor excreted by the renal tubules when present in the glomerular filtrate in the concentration range of 13.3 to $66.6 \mathrm{mg}$. per $100 \mathrm{cc}$.

Newman, Gilman, and Philips (2) subsequently reported a series of simultaneous inulin and thiosulphate clearances in man. Using the single injection method, they found that the thiosulphate/ inulin clearance ratio fell within the range of 0.7 to 1.3 (average $0.99 \pm 0.08$ ) and that this ratio was independent of the plasma concentration between 6 and $60 \mathrm{mg}$. per $100 \mathrm{cc}$. The apparent identity of these clearances has been confirmed by Brun (3), Crawford (4), and Blegen, Ørning, and Aas (5), while Bjфrnboe, Dalgaard-Mikkelsen, and Raaschou (6) report that in three subjects the thiosulphate/inulin clearance ratio is higher when the urine is alkaline than when it is acid.

More recently, Pitts and Lotspeich (7), employing thiosulphate to measure the filtration rate in dogs in connection with studies of acid-base balance, confirmed the identity of the thiosulphate, creatinine clearance ratio (average 1.00 , range 0.90 to 1.13 ) in this species, and stated that the administration of thiosulphate did not disturb either glomerular filtration or renal plasma flow.

Since it appeared from this evidence that the thiosulphate clearance is a reliable measure of glomerular filtration rate, and since inulin was not obtainable in post-war Europe, a study of renal function in normal and toxemic pregnancy was

\footnotetext{
1 Graduate Fellow of the Belgian-American Educational Foundation.
}

started by one of us (C. L.) in Brussels in 1947, using this clearance for the measurement of the filtration rate.

\section{METHODS}

Studies were performed on 49 adult, female patients from the Saint-Pierre Hospital (Brussels) and the Gynecological and Obstetrical Services of the Sloane Hospital for Women (New York). Forty-two of these patients were pregnant, the period of gestation ranging from six weeks to term; with the exception of two cases of preeclampsia, all presented normal pregnancies. Four were in early puerperium. In addition, three normal, nonpregnant women were examined.

All of the above subjects were receiving the regular ward diet except for 22 of the pregnant group who were on a low salt diet. They were examined in the recumbent position and had received nothing but water since the evening meal before the test. Immediately before the test they drank $200 \mathrm{cc}$. of water and this fluid, with the constant infusion, maintained a satisfactory urine flow averaging about $2 \mathrm{cc}$. per minute.

Four normal female dogs were also studied. In addition, one pregnant animal was followed at different stages of pregnancy.

Renal clearances were performed in the usual manner, with serial clearance periods varying from 10 to $30 \mathrm{~min}$ utes. Urine was collected by catheter and the bladder was washed with distilled water and air. A renal delay time of 2.5 minutes was used in the calculation of renal clearances. In earlier experiments a single intravenous injection of inulin and sodium thiosulphate was given, but, in later experiments, a continuous infusion was used in order to provide constant or increasing plasma concentrations of thiosulphate. p-Aminohippurate (PAH) was administered subcutaneously when clearance levels were desired, and intravenously by constant infusion when the aim was to saturate the tubule cells by high plasma levels. 4'-Carboxyphenylmethanesulfonanilide (carinamide) was given by mouth to humans and by mouth or intravenously to dogs.

PAH was determined by the method of Smith and his associates (8), thiosulphate by the iodometric reaction described by Gilman, Philips, and Koelle (1) and also by the direct iodine titration of Holbøll (9) and Claus Brun (10). As most of our observations involved low plasma concentrations of thiosulphate, recoveries were carefully 
checked. Analytical aliquots of plasma and urine were of such size that the difference between the blank and the unknown was at least $1 \mathrm{cc}$. $(0.158 \mathrm{mg}$. of thiosulphate standard solution). The difference between duplicates, when analyzed by the two methods cited above, was never greater than 4 per cent. Lebrun (11), working at plasma concentrations ranging between 5 and $12 \mathrm{mg}$. and using the analytical method of Gilman and his coworkers, reports an average error of only 0.5 per cent for his thiosulphate recoveries.

The plasma thiosulphate blanks varied from 1.5 to 2.5 mg. per 100 cc.; the urine blank was always below 10 mg. per $100 \mathrm{cc}$., averaging $4 \mathrm{mg}$. per $100 \mathrm{cc}$., yielding an average blank clearance of 0.5 to $0.7 \mathrm{mg}$. per minute. These figures are no higher than those obtained by Newman, Gilman and Philips (2).

In the presence of high plasma concentrations of $\mathrm{PAH}$, sodium thiosulphate was determined by the indirect method (1) with the modifications introduced by Elliott and Scott (12). Numerous recoveries of known amounts of thiosulphate in plasma containing 50 to $80 \mathrm{mg}$. per 100 cc. of PAH showed an error averaging +1.5 per cent, and never exceeding +4 per cent. Excellent thiosulphate recoveries were obtained in plasma samples containing $2 \mathrm{gm}$. per $100 \mathrm{cc}$. of carinamide.

Inulin was determined by the method of Alving, Rubin, and Miller (13), using unyeasted trichloracetic filtrates. Recoveries of known amounts of inulin added to plasma showed an average error of 4.5 per cent, ranging between 3 and 6 per cent.

The plasma inulin blank ranged between 1.5 and $3 \mathrm{mg}$. per $100 \mathrm{cc}$., the highest value being $4 \mathrm{mg}$. per $100 \mathrm{cc}$. The urine blanks were often negligible, and never higher than $5 \mathrm{mg}$. per $100 \mathrm{cc}$. The rate of excretion of inulinoid blank, for which correction was introduced whenever a significant urine blank was present, ranged between 0.1 and $0.3 \mathrm{mg}$. per minute.

\section{RESULTS}

\section{Thiosulphate Clearance in Pregnant Women}

Seventy-three clearance determinations were made on 20 pregnant women at periods of gestation ranging from six weeks to term. In some instances a single intravenous injection of thiosulphate was used in order to examine the excretion of thiosulphate during decreasing plasma concentrations. In other instances a continuous infusion was used to maintain the plasma concentration at a constant level. Considering all tests, the thiosulphate plasma concentration varied from 3.5 to $43.2 \mathrm{mg}$. per $100 \mathrm{cc}$. The average thiosulphate clearance in 17 periods with the plasma concentration below $17 \mathrm{mg}$. per $100 \mathrm{cc}$. was $227 \mathrm{cc}$. per minute. In 56 clearance periods in which the thiosulphate plasma concentration was above 17 mg. per $100 \mathrm{cc}$. the average clearance value was $140 \mathrm{cc}$. per minute. This discrepancy suggested that the thiosulphate clearance might be higher at low than at elevated plasma concentrations. Moreover, irrespective of the plasma concentration, our average figures for the thiosulphate clearance are substantially higher than the average filtration rate, 116 to $124 \mathrm{cc}$. per minute, in pregnant women, as measured by the inulin clearance (14, 15).

\section{Thiosulphate/Inulin Clearance Ratio in Pregnant Women}

It appeared desirable to investigate the possibility of tubular excretion of thiosulphate in pregnancy by the simultaneous estimation of thiosulphate and inulin clearances using falling, constant, or increasing plasma concentrations of sodium thiosulphate. Therefore, simultaneous inulin and thiosulphate clearances were determined in 20 pregnant women, the period of gestation ranging from 20 to 36 weeks. Two of these presented symptoms of toxemia of pregnancy. Four women were also studied postpartum.

In 16 tests, 53 clearance periods were obtained during decreasing blood thiosulphate and inulin concentrations following a single intravenous injection of both substances (Figure 1). In 13 of these tests, PAH was administered by subcutaneous injection to yield low plasma levels $(3 \mathrm{mg}$. per $100 \mathrm{cc}$.). The serum concentration of thiosulphate varied from 33 to $3 \mathrm{mg}$. per $100 \mathrm{cc}$. The thiosulphate/inulin clearance ratio, averaging about 1.0 at plasma thiosulphate concentrations above $18 \mathrm{mg}$. per $100 \mathrm{cc}$., increased as the thiosulphate concentration was reduced, to reach values in excess of 1.4 at plasma concentrations of $8 \mathrm{mg}$. per $100 \mathrm{cc}$. or less. Much the same relation was observed when the plasma concentration of both thiosulphate and inulin were kept constant by intravenous infusion. Thirty-two clearance periods were obtained in eight women in the 21 st to 36th week of pregnancy. In 26 periods determined with the constant infusion method and thiosulphate plasma levels ranging from 4 to $15 \mathrm{mg}$. per $100 \mathrm{cc}$., the average clearance ratio was 1.25 . In six periods in which the level was maintained above $26.5 \mathrm{mg}$. per $100 \mathrm{cc}$., the average clearance ratio was 1.08 . 


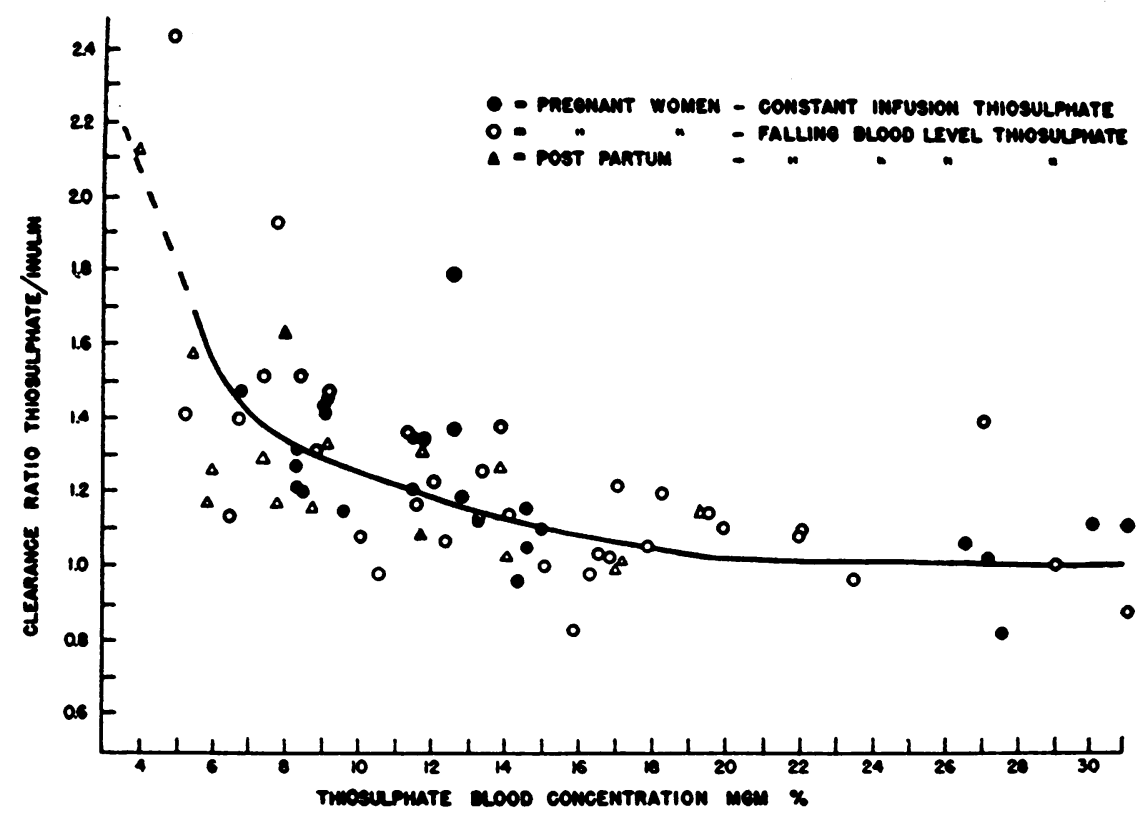

Fig. 1. Relation Between Thiosulphate/Inulin Clearance Ratio and Thiosulphate Prasma Concentration in Women Examined During Pregnancy or Postpartum

Figure 2 shows a typical series of determinations in one woman in the 36 th week of pregnancy. The clearance ratio averaged 1.47 at a thiosulphate plasma concentration of $7 \mathrm{mg}$. per $100 \mathrm{cc}$., and approached 1.0 when this figure reached $25 \mathrm{mg}$. per $100 \mathrm{cc}$.

\section{Effects of Carinamide on Thiosulphate Excretion}

4'-Carboxyphenylmethanesulfonanilide (carinamide) is known to inhibit tubular excretion (1619). In one patient in the 25 th week of pregnancy, examined after a single injection of thiosulphate, the thiosulphate/inulin clearance ratio averaged 1.24 ; when examined two weeks later after receiving $0.5 \mathrm{gm}$. of carinamide orally every four hours for 16 hours before the test, and $2 \mathrm{gm}$. one hour before the test, the clearance ratio averaged 0.78 . In both cases the range of plasma thiosulphate concentration was from 17 to $7 \mathrm{mg}$. per 100 cc. The PAH clearance was depressed by the carinamide from 672 to $295 \mathrm{cc}$. per minute.

\section{Depression of the Thiosulphate Clearance by $P A H$}

It is known that saturation of the tubular transport system with one substance tends to depress the tubular excretion of other substances (20). Consequently the thiosulphate/inulin clearance ra- tio was determined before and during tubular saturation with $\mathrm{PAH}$ in five pregnant women, using the constant infusion technique. After three control periods, a quantity of $\mathrm{PAH}$ sufficient to bring the $\mathrm{PAH}$ plasma concentration in four pa-

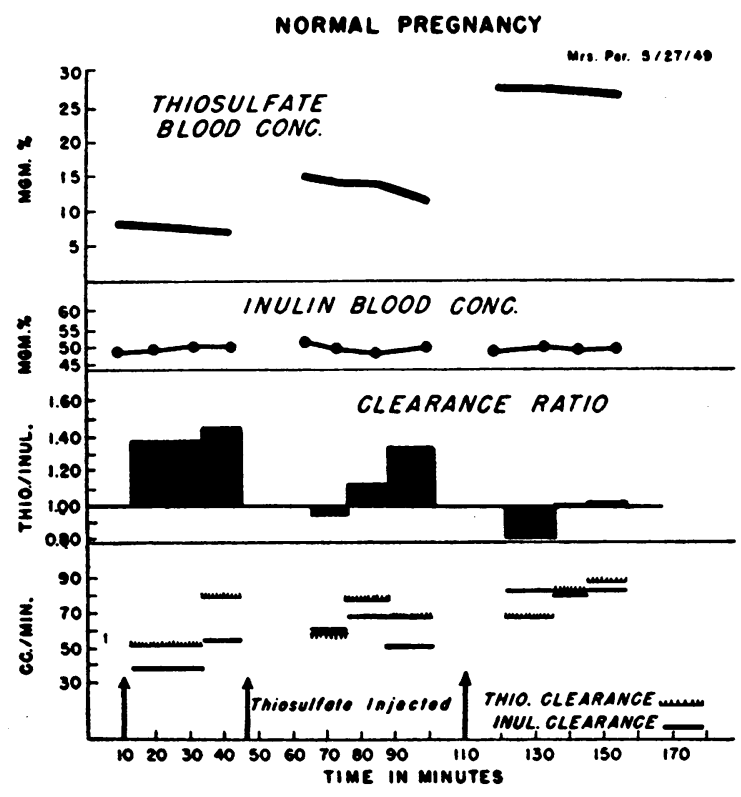

Fig. 2. Effect of Elevation of the Plasma Thiosulphate Concentration on the Thiosulphate/INUlin Clearance Ratio 


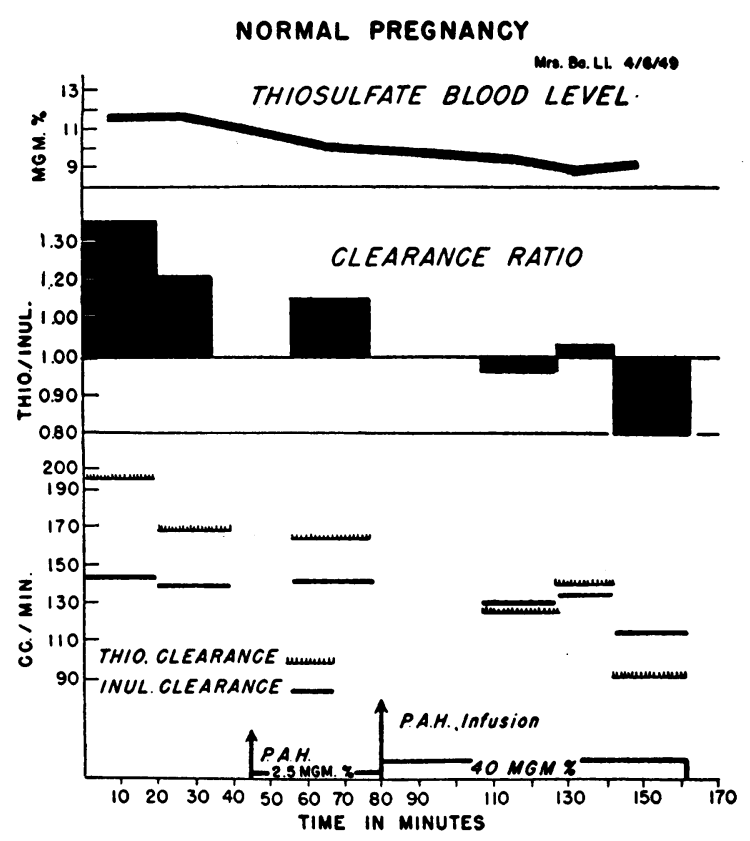

Fig. 3. Action of PAH at High Plasma Concentrations on the Thiosulphate/Inulin Clearance RATIo

tients to $38 \mathrm{mg}$. per $100 \mathrm{cc}$. or higher was administered. The thiosulphate/inulin clearance ratio before and after saturation with $\mathrm{PAH}$ in the first patients was 1.44 and 1.03 , in the second 1.46 and 1.13 , in the third 1.10 and 0.78 , and in the fourth 1.45 and 1.08. In the fifth patient, a plasma $\mathrm{PAH}$ concentration of 28 to $31 \mathrm{mg}$. per $100 \mathrm{cc}$. reduced this clearance ratio from 1.31 to 1.20. An experiment on a sixth patient in the $21 \mathrm{st}$ week of pregnancy is illustrated in Figure 3 . At a nearly constant plasma thiosulphate concentration of 9 to $11 \mathrm{mg}$. per $100 \mathrm{cc}$., elevation of the plasma PAH concentration from 2.5 to $40 \mathrm{mg}$. per $100 \mathrm{cc}$. depressed the thiosulphate/inulin clearance ratio from 1.26 to 0.93 .

\section{Observations during the Postpartum Period and in Non-pregnant Women}

In three women, six to eight days postpartum, the thiosulphate/inulin clearance ratio was in the same range as observed during pregnancy. Using decreasing plasma concentrations varying from 17 to $8 \mathrm{mg}$. per $100 \mathrm{cc}$., the average clearance ratios were $1.25,1.41$, and 1.13 . In another patient 26 days postpartum, the thiosulphate/inulin clear- ance ratio averaged 1.10 at a thiosulphate plasma level falling from 17 to $11.7 \mathrm{mg}$. per $100 \mathrm{cc}$.

Thiosulphate/inulin clearance ratios were determined in three non-pregnant women. The constant infusion technique was used in two, with increasing amounts of thiosulphate added in the later periods, thus starting with a low plasma concentration and ending with a high one. With low thiosulphate plasma concentrations ( 3 and 6 mg. per $100 \mathrm{cc}$.) the clearance ratios averaged 2.20 and 1.51 , respectively; with a high plasma concentration ( $40 \mathrm{mg}$. per cent), these ratios were 1.09 and 1.02 , respectively.

\section{Observations in the Dog}

In nine control observations on a pregnant bitch, obtained on two occasions at plasma thiosulphate concentrations of 4.5 to $12.3 \mathrm{mg}$. per 100 cc., the thiosulphate/inulin clearance ratio ranged from 0.91 to 1.45 . After carinamide ( $50 \mathrm{mg}$. per $\mathrm{kg}$. orally or intravenously every hour for 10 hours) this ratio ranged from 0.52 to 0.85 in 10 observations made on three occasions.

Twelve clearances were determined in five nonpregnant female dogs, using the constant infusion method. The thiosulphate/inulin clearance ratio averaged 1.03 at plasma thiosulphate concentrations ranging from 5 to $54 \mathrm{mg}$. per $100 \mathrm{cc}$. After three control periods in these same dogs, a quantity of PAH sufficient to bring the plasma PAH concentration to 25 to $50 \mathrm{mg}$. per $100 \mathrm{cc}$. was added to the infusion. The thiosulphate/inulin clearance ratio in eight such clearance periods was depressed to an average of 0.89 .

\section{DISCUSSION}

Our data show that the average thiosulphate clearance in pregnant women is substantially greater than the recorded values of the inulin clearance, this descrepancy being greater at low than at high plasma concentrations of thiosulphate. In simultaneous observations, the thiosulphate/ inulin clearance ratio has an average value of the order of 1.4 (range 1.1 to 1.6) at plasma thiosulphate concentrations of 6 to $10 \mathrm{mg}$. per $100 \mathrm{cc}$., this ratio being depressed to about 1.0 at plasma concentrations of $20 \mathrm{mg}$. per $100 \mathrm{cc}$. This relationship is independent of whether the plasma concentration is falling, rising, or maintained at a con- 
stant level by infusion. The clearance ratio is depressed, sometimes below 1.0 , by saturation of the tubules with $\mathrm{PAH}$, and even more markedly depressed (to 0.78 in one instance) by carinamide.

Clearance ratios above 1.0 at low plasma concentrations were also observed in women examined postpartum, and in three non-pregnant women, but our data and those of Lebrun (11) suggest that this ratio is somewhat lower at higher plasma concentrations in non-pregnant women.

In one pregnant dog, the clearance ratio ranged from 0.91 to 1.45 before carinamide, and from 0.52 to 0.85 after administration of this drug. In five non-pregnant bitches, the clearance ratio averaged 1.03, and was depressed in these animals by carinamide to an average value of 0.89 .

A high thiosulphate clearance, and an apparent relation between clearance and thiosulphate plasma concentration, might be explained by assuming that $(a)$ thiosulphate is synthesized by the kidney or $(b)$ that thiosulphate is excreted by the tubules.

The possibility that thiosulphate is synthesized by the kidney from thioamino acids by the enzymatic process described by Garabedian and his colleagues (21-23) is improbable, because in such a case one would expect a similar increase in sulphate excretion. But in pregnancy, according to Crabtree (24) and Werboff (25), the sulphate excretion is decreased, despite an increase in the sulphate concentration in the blood $(26,27)$. Better evidence that thiosulphate is not synthesized to an appreciable extent by the kidney is afforded by the fact that thiosulphate blank excretion in pregnant women is low ( 0.5 to $0.7 \mathrm{mg}$. per minute) and of the same order as reported by Newman, Gilman, and Philips (2). This blank excretion is insufficient to raise the thiosulphate/inulin clearance to the magnitude observed here, even at our lowest plasma thiosulphate concentrations. The only probable interpretation of the high thiosulphate/inulin clearance ratio is tubular excretion of preformed thiosulphate.

Our results can best be interpreted, therefore, as indicating that in women thiosulphate is excreted in part by the renal tubules, by a process which is depressed by $\mathrm{PAH}$ and carinamide, and that this tubular process is readily overloaded by elevation of the plasma thiosulphate concentration, depressing the thiosulphate/inulin clearance ratio. The relation between tubular and glomerular clearance is such that, at the plasma concentrations examined by Newman, Gilman, and Philips (2) and others, the thiosulphate/inulin clearance ratio has a value in the range of 0.9 to 1.1. Our data suggest, but do not prove, that tubular excretion is enhanced during pregnancy.

Our observations on the dog, contrary to those of Gilman, Philips, and Koelle (1) and Pitts and Lotspeich (7), suggest that tubular excretion also occurs in this species (as indicated notably by depression of the thiosulphate/inulin clearance ratio by carinamide).

The fact that the thiosulphate/inulin clearance ratio in both women and dogs may be depressed substantially below 1.0 by carinamide indicates that, under this circumstance at least, filtered thiosulphate may undergo some tubular reabsorption. Simultaneous tubular excretion and reabsorption of potassium has been demonstrated by Mudge, Foulks, and Gilman (28) and Berliner and Kennedy (29), and such a multiple system has been postulated by Beyer and his coworkers to explain the excretion of carinamide itself $(30,31)$.

Many years ago Marshall (32) reported that thiosulphate is excreted by the aglomerular fish kidney, and, since these studies were initiated, Bing and Effersøe (10), although finding no evidence of tubular excretion in the rabbit, demonstrated tubular excretion in the cat, an observation which has been confirmed by Eggleton and Habib (33). Evidence in favor of tubular excretion in man has been adduced by Lebrun (11), who reports an average thiosulphate/mannitol clearance ratio of 1.34 in 51 clearance periods on 16 subjects (sex not stated), the plasma concentration being maintained below $12 \mathrm{mg}$. per $100 \mathrm{cc}$. Carinamide depressed this ratio to an average value of 0.95 . It seems, therefore, that the phenomenon is not specifically related to pregnancy.

\section{SUMMARY}

1. The thiosulphate clearance, calculated from 151 clearances performed on 42 pregnant women, averaged $150 \mathrm{cc}$. per minute. In 53 simultaneous determinations, the thiosulphate/inulin clearance ratio averaged 1.33. This clearance ratio approaches unity at a thiosulphate plasma concentration exceeding $16 \mathrm{mg}$. per $100 \mathrm{cc}$. 
2. Administration of adequate quantities of PAH or carinamide depresses the thiosulphate/ inulin clearance ratio to or below 1.0. From this evidence we conclude that thiosulphate is excreted by the tubules in pregnant and non-pregnant women.

3. The fact that carinamide sometimes depresses the clearance ratio to values substantially below 1.0 in pregnant women indicates that, at least under these conditions, filtered thiosulphate can be reabsorbed by the tubules.

4. As judged by the action of carinamide, tubular excretion of thiosulphate occurs in pregnant and non-pregnant female dogs.

\section{ACKNOWLEDGMENTS}

The authors are indebted to Professor Homer W. Smith for his advice and guidance, and to Professors Howard C. Taylor and Jean Snoeck, in whose departments this work was carried out. They wish to thank Dr. Morton H. Maxwell for his assistance in the preparation of this manuscript.

\section{BIBLIOGRAPHY}

1. Gilman, A., Philips, F. S., and Koelle, E. S., The renal clearance of thiosulfate with observations on its volume of distribution. Am. J. Physiol., 1946, 146, 348.

2. Newman, E. V., Gilman, A., and Philips, F. S., The renal clearance of thiosulfate in man. Bull. Johns Hopkins Hosp., 1946, 79, 229.

3. Brun, C., Thiosulphate as a measure of the glomerular filtration rate in normal and diseased human kidneys. Acta med. Scandinav., 1949, Supp. 234, 63.

4. Crawford, B., Depression of the exogenous creatinine/inulin or thiosulfate clearance ratios in man by diodrast and $p$-aminohippuric acid. J. Clin. Invest., 1948, 27, 171.

5. Blegen, E., Ørning, K., and Aas, K., The renal clearance of thiosulfate in man. Scandinav. J. Clin. Lab. Invest., 1949, 1, 102.

6. Bjфrneboe, M., Dalgaard-Mikkelsen, S., and Raaschou, F., Does the filtration (thiosulfate clearance) differ at different $\mathrm{pH}$ values in the urine? Scandinav. J. Clin. Lab. Invest., 1949, 1, 347.

7. Pitts, R. F., and Lotspeich, W. D., The use of thiosulfate clearance as a measure of glomerular filtration rate in acidotic dogs. Proc. Soc. Exper. Biol. \& Med., 1947, 64, 224.

8. Smith, H. W., Finkelstein, N., Aliminosa, L., Crawford, B., and Graber, M., The renal clearances of substituted hippuric acid derivatives and other aromatic acids in dog and man. $\mathrm{J}$. Clin. Invest., 1945, 24, 388.
9. Holbøll, S. A., Quantitative determinations of sodium thiosulfate in the urine. Klin. Wchnschr., 1925, 4, 1636.

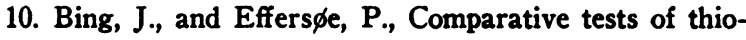
sulfate and creatinine clearance in rabbits and cats. Acta physiol. Scandinav., 1948, 15, 231.

11. Lebrun, J., Etude de la clearance de l'hyposulfite de soude chez l'homme à basse concentration sanguine. J. d'Urol., 1949, 55, 745.

12. Elliott, S. R., II, and Scott, H. W., Jr., Effect of paraaminohippuric acid on sodium thiosulfate determinations in renal clearance studies. Bull. Johns Hopkins Hosp., 1948, 83, 213.

13. Alving, A. S., Rubin, J., and Miller, B. F., A direct colorimetric method for the determination of inulin in blood and urine. J. Biol. Chem., 1939, 127, 609.

14. Welsh, C. A., Wellen, I., and Taylor, H. C., Jr., The filtration rate, effective renal blood flow, tubular excretory mass and phenol red clearance in normal pregnancy. J. Clin. Invest., 1942, 21, 57.

15. Dill, L. V., Isenhour, C. E., Cadden, J. F., and Schaffer, N. K., Glomerular filtration and renal blood flow in the toxemias of pregnancy. Am. J. Obst. \& Gynec., 1942, 43, 32.

16. Beyer, K. H., New concept of competitive inhibition of the renal tubular excretion of penicillin. Science, 1947, 105, 94.

17. Beyer, K. H., Miller, A. K., Russo, H. F., Patch, E. A., and Verwey, W. F., The inhibitory effect of caronamide on the renal elimination of penicillin. Am. J. Physiol., 1947, 149, 355.

18. Beyer, K. H., Russo, H. F., Patch, E. A., Tillson, E. K., and Shaner, G., Certain pharmacologic properties of $4^{\prime}$ carboxyphenylmethanesulfonanilide (caronamide), including its effect on the renal clearance of compounds other than penicillin. J. Pharmacol. \& Exper. Therap., 1947, 91, 272.

19. Rapoport, M., Corneal, M. B., Beyer, K. H., and Verwey, W. F., A clinical evaluation in children of the toxicity and efficacy of caronamide ( $4^{\prime}$ carboxyphenylmethanesulfonanilide) for the competitive inhibition of penicillin excretion. Am. J. M. Sc., 1948, 215, 514.

20. Smith, H. W., Lectures on the Kidney. University Extension Division, University of Kansas, Lawrence, Kansas, 1943.

21. Garabedian, M. D., and Fromageot, C., Oxydation de l'hydrogène sulfuré en hyposulfite chez les animaux supérieurs. Compt. rend. Acad. sc., 1943, 216, 216.

22. Garabedian, M. D., Oxydation de l'ion sulfure ( $\mathrm{S}^{-}$) en thiosulfate $\left(\mathrm{S}^{2} \mathrm{O}^{2-}\right)$ chez les animaux supérieurs. Conditions d'activité et de préparation du système oxydant. Compt. rend. Soc. de biol., 1944, 138, 399.

23. Garabedian, M. D., and Gonnard, P., Oxidation of sulfides to thiosulfates in the higher vertebrates Compt. rend. Soc. de biol., 1945, 139, 311. 
24. Crabtree, E. G., Urological Diseases of Pregnancy. Little, Brown \& Co., Boston, 1942.

25. Werboff, S., Nierentuberkulose und Schwangerschaft. Ztschr. f. Urol., 1925, 19, 496.

26. Goudsmit, A., and Keith, N. M., Relative significance of concentration of inorganic sulfate in the serum and its renal clearance, with special reference to diffuse arteriolar disease with hypertension. Arch. Int. Med., 1940, 66, 816.

27. Anderson, D. F., and Tompsett, S. L., Observations on the inorganic sulphate content of the blood in eclampsia. Brit. J. Exper. Path., 1932, 13, 130.

28. Mudge, G. H., Foulks, J., and Gilman, A., The renal excretion of potassium. Proc. Soc. Exper. Biol. \& Med., 1948, 67, 545.

29. Berliner, R. W., and Kennedy, T. J., Jr., Renal tubu- lar secretion of potassium in the normal dog. Proc. Soc. Exper. Biol. \& Med., 1948, 67, 542.

30. Beyer, K. H., Russo, H. F., Tillson, E. K., Gass, S. R., and Schuchardt, G. S., Caronamide (4'-carboxyphenylmethanesulfonanilide): its renal clearance and binding on plasma protein. Am. J. Physiol., 1949, 159, 181.

31. Peck, H. M., Tillson, E. K., Waller, W. S., and Beyer, K. H., The renal extraction and excretion of caronamide (4'-carboxyphenylmethanesulfonanilide). J. Lab. \& Clin. Med., 1950, 35, 87.

32. Marshall, E. K., Jr., The comparative physiology of the kidney in relation to theories of renal secretion. Physiol. Rev., 1934, 14, 133.

33. Eggleton, M. G., and Habib, Y. A., Thiosulfate clearance in the cat. J. Physiol., 1949, 108, $46 P$. 